Article

\title{
Wear and Deformation Performance of W/Ta Multilayer Coatings on Pure Cu Prepared by Double Glow Plasma Alloying Technique
}

\author{
Bo Dang, Tian Tian, Kai Yang, Feng Ding, Fengkun Li, Dongbo Wei ${ }^{\circledR}$ and Pingze Zhang * \\ College of Materials Science and Technology, Nanjing University of Aeronautics and Astronautics, \\ Nanjing 211106, China; dangbo@nuaa.edu.cn (B.D.); bx1706512@nuaa.edu.cn (T.T.); ykcl@nuaa.edu.cn (K.Y.); \\ dingf@nuaa.edu.cn (F.D.); lifengkun@nuaa.edu.cn (F.L.); weidongbo@nuaa.edu.cn (D.W.) \\ * Correspondence: zhangpingze@nuaa.edu.cn; Tel.: +86-139-5188-3686
}

Received: 3 September 2020; Accepted: 24 September 2020; Published: 27 September 2020

\begin{abstract}
In this study, a multilayered hard coating with a tungsten matrix and a transition layer was deposited on pure copper by double glow plasma surface alloying technology, which aimed to provide the coating superior binding force and favorable matching of mechanical properties. The micro-hardness tester was adopted to measure the surface and cross-sectional hardness of the coatings. The nanoindentation test was used to measure the elasticity modulus of the coatings. Sliding wear tests under different conditions were performed on the W/Ta multilayer coating as well as the $\mathrm{Cu}$ substrate and $\mathrm{W}$ coating. The fairly low specific wear rate of the multilayer coating proved its excellent wear-resisting property, and the wear mechanism of the multilayer coating was mainly abrasive wear. In addition, a scratch test was executed to evaluate the deformation mechanism of the coating. Compared to the $\mathrm{W}$ coating, the persistence of the changing elastic-plastic deformation in the W/Ta multilayer coating improved the adhesion and resistance to plastic deformation. Moreover, the changing elastic-plastic deformation region is a benefit to the wear process, and the mechanical properties of the transition layer present a linear gradient descent instead of a vertical gradient, which makes a significant contribution in the wear stage. Further, the exploration of deformation mechanisms has a significant contribution to the design for multilayered hard coatings.
\end{abstract}

Keywords: W/Ta multilayer coating; transition layer; wear; deformation mechanism

\section{Introduction}

In recent years, with the implementation of the International Thermonuclear Experimental Reactor plan, plasma-facing materials (PFM) have attracted considerable attention [1,2]. It was reported that the combination of hard alloy coating and the substrate of heat sink material have been used as the PFM of the divergent components in fusion reactors due to their high melting point, high sputtering and wear resistance, good thermal conductivity, and other outstanding comprehensive performances [3-5]. As an important research direction of PFM, $\mathrm{W}$ coating on copper substrate has very important research and application value, which can protect the vacuum interior wall and various internal components from high-temperature plasma-direct irradiation [6,7].

Therefore, various methods have been proposed in an attempt to fabricate a $\mathrm{W}$ coating on the $\mathrm{Cu}$ substrate, such as mechanical alloying, the chemical vapor deposition (CVD) technique, and the physical vapor deposition (PVD) technique. Liu et al. [8] reported that the W coating was deposited on $\mathrm{Cu}$ alloy using the electro-deposition technique, which was compact and uniform without any impurities. Monclús et al. [9] investigated the microstructure and mechanical properties of $\mathrm{Cu} / \mathrm{W}$ multilayers deposited by balanced magnetron sputtering apparatus, and the results showed that the 
hardness was not dependent on the layer thickness and declined speedily with temperature in contrast with $\mathrm{Cu} / \mathrm{Nb}$ nanoscale metallic multilayers. Wang et al. [10] reported that a $\mathrm{W}$ coating was deposited on $\mathrm{CuCrZr}$ alloy by the vacuum plasma spraying technique with a Ti interlayer, which presented excellent performance in the thermal response test with a heat flux. These indicate that the $\mathrm{W}$ coating deposited by various surface modification methods on the $\mathrm{Cu}$ substrate has gradually become the preferred material for their potential use in the nuclear industry.

However, since $\mathrm{W}$ and $\mathrm{Cu}$ have no solubility of each other through the whole composition, and they have distinct differences in physical properties such as melting point, elasticity modulus, and thermal expansion coefficient, it is very difficult to realize the direct metallurgical combination of the $\mathrm{W}$ coating and $\mathrm{Cu}$ substrate by the current conventional process [11]. This results in their poor adhesion, which is easily cracked or peeled, limiting their applications. Thus, it is critical to take appropriate measures to design and probe a new coatings matrix for further development. In our previous work, coatings obtained by double glow plasma (DGP) surface alloying technology exhibited a satisfactory combinative ability to the substrate. Qiu et al. [12] found that the W-Mo coating was metallurgically bound to the gear steel substrate and had excellent wear resistance. Yi's investigations [13] demonstrated that the pre-processing of $\mathrm{Nb}$ diffusion in $\mathrm{NbN}$ coating by the DGP surface alloying technology presented an advantageous bond strength, mechanical property, and wear resistance performance. It can be deduced that various metal coatings, including immiscible metals, can be directly metallurgically combined with the substrate by the way of DGP surface alloying treatment technology.

In this study, DGP surface alloying technology was applied to obtain a good adhesion coating on the substrate. Simultaneously, in order to overcome the failures of $\mathrm{W}$ coating on the $\mathrm{Cu}$ substrate as a result of their huge differences in physical performance, an interlayer was designed to realize the transition of mechanical properties between $\mathrm{W}$ and $\mathrm{Cu}$ to achieve better comprehensive performance. Then, a Ta layer was chosen as the transition interlayer, because it has an intermediate hardness, elasticity modulus, and thermal expansion coefficient, and it can form the infinite solid solution with tungsten $[14,15]$. Accordingly, a W/Ta multilayer coating was designed and deposited on pure copper using DGP surface alloying technology to achieve the above objectives. Moreover, the constitutive relationship in the course of variational loading was inferred by means of a scratch test, and the relationship between the microstructure, mechanical properties, and tribological behavior of coatings was discussed in this paper. More importantly, an in-depth understanding of this issue may provide a clear design concept in the multilayer design.

\section{Materials and Methods}

\subsection{Coating Deposition}

The substrate was pure $\mathrm{Cu}$ with the size of $15 \mathrm{~mm} \times 15 \mathrm{~mm} \times 4 \mathrm{~mm}$. A double glow plasma surface alloying chamber was applied to deposit $\mathrm{W} / \mathrm{Ta}$ multilayer coatings on pure $\mathrm{Cu}$, which installed an anode (the vacuum chamber) and a source electrode (Ta or W target, $\Phi 100 \mathrm{~mm} \times 5 \mathrm{~mm}$, purity of 99.95\%), as shown in Figure 1. The transition layer (Ta interlayer) was firstly prepared by DGP; based on that, a W coating was deposited. The parameters of DGP tantalum and tungsten surface alloying treatment technology are shown in Table 1.

\subsection{Mechanical Test}

The micro-hardness of the surface and cross-section of specimens were measured by a micro-hardness tester (HXS-1000AY, Shanghai Optical Instrument Co., Ltd., Shanghai, China) with a load of $100 \mathrm{~g}$ and a dwell time of $5 \mathrm{~s}$. The elastic modulus of the samples was executed by a Nano Indenter System (NHT ${ }^{3}$, Anton Paar, Graz, Austria) with a Berkovich indenter at the peak load of $10 \mathrm{mN}$ and the constant loading rate of $0.33 \mathrm{mN} / \mathrm{s}$. A standard scratch test was accomplished by a micro-scratch tester (MST ${ }^{3}$, Anton Paar, Austria) at a sliding speed of $166.7 \mu \mathrm{m} / \mathrm{s}$ with a loading rate 
of $1 \mathrm{~N} / \mathrm{s}$ from $30 \mathrm{mN}$ to $30 \mathrm{~N}$ throughout the scratch course to evaluate the adhesion strength and deformation mechanism of coatings.

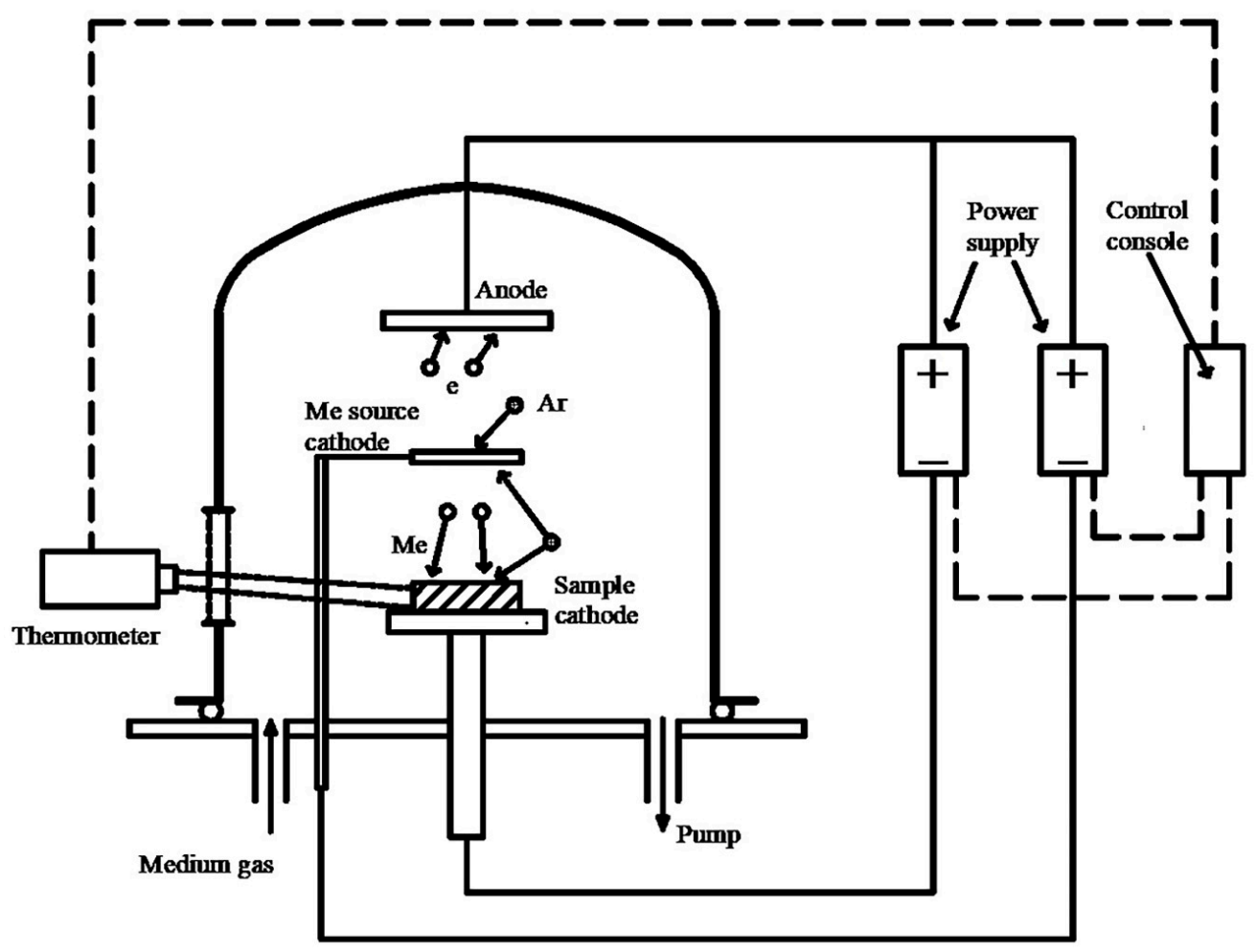

Figure 1. Schematics of the basic hardware setup for DGP surface alloying technology.

Table 1. Process parameters of double glow plasma (DGP) tantalum and tungsten surface alloying treatment technology.

\begin{tabular}{ccc}
\hline \multicolumn{2}{c}{ Process Parameters and Their Corresponding Values } \\
\hline Target & Ta $(99.95 \%)$ & W $(99.95 \%)$ \\
Temperature $(\mathrm{K})$ & 1123 & 1123 \\
Time $(\mathrm{h})$ & 3 & 3 \\
Working pressure (Pa) & 38 & 40 \\
Distance between the source and substrate $(\mathrm{mm})$ & 15 & 18 \\
Voltage of the target $(\mathrm{V})$ & $800-850$ & $850-900$ \\
Voltage of the substrate $(\mathrm{V})$ & $500-520$ & $450-500$ \\
\hline
\end{tabular}

\subsection{Wear Test}

The tribological test at room temperature $\left(25^{\circ} \mathrm{C}\right)$ was conducted on the material surface performance tester (CFT-I, Lanzhou Zhongke Kaihua Technology Development, Co., Ltd., Lanzhou, China) using a fixture in a linear reciprocation pattern. The test parameters were a load of $4.2 \mathrm{~N}$, sliding counter body of GCr15 ball with the diameter of $5 \mathrm{~mm}$, sliding speed of $4 \mathrm{~m} / \mathrm{min}$, and duration time of $15 \mathrm{~min}$. The friction-wear test at the temperature of $500{ }^{\circ} \mathrm{C}$ was conducted on a ball-on-disk high temperature wear tester (HT-500, Lanzhou Zhongke Kaihua Technology Development, Co., Ltd., Lanzhou, China). The test parameters were a load of $4.2 \mathrm{~N}$, speed of $460 \mathrm{rpm} / \mathrm{min}$, friction pair of GCr15 ball with the diameter of $5 \mathrm{~mm}$, rotation radius of $2 \mathrm{~mm}$, and duration time of $10 \mathrm{~min}$.

The wear rates were calculated from Equation (1):

$$
K=\frac{V}{F L}
$$


where $K$ is the wear rate $\left(\mathrm{mm}^{3} / \mathrm{Nm}\right), V$ is the wear volume $\left(\mathrm{mm}^{3}\right), F$ is the normal load $(\mathrm{N})$, and $L$ is the total sliding distance $(\mathrm{m})$.

\subsection{Surface Characterication}

The morphologies of the coatings and the wear scar morphologies were observed via scanning electron microscopy (SEM, JSM-6300, JEOL, Tokyo, Japan) with an energy-dispersive spectrometer (EDS). The phase compositions of the samples were examined by X-ray diffraction (XRD, XRD-6100, Shimadzu, Kyoto, Japan) with $\mathrm{Cu} \mathrm{K} \alpha$ radiation at $40 \mathrm{kV}$ and $20 \mathrm{~mA}$, in Bragg-Brentano geometry $\left(2 \theta-20-90^{\circ}\right)$ at a step scan of $0.1^{\circ} / \mathrm{s}$.

\section{Results and Discussion}

\subsection{Microstructure and Phase Distribution}

The typical surface features of $\mathrm{W}$ coating with a mass of protuberant particles are shown in Figure 2a, and its corresponding cross-sectional morphology is given in Figure 2d, in which a great deal of cracks and comminutions can be distinctly observed. This is attributed to the distinct differences in thermodynamic and mechanical properties between $\mathrm{W}$ and $\mathrm{Cu}$, which have been described in the literature [16]. Meanwhile, as presented in Figure 2b,e, the Ta coating reveals the uniform dense surface, and this interface is devoid of any defects (such as cracks, pores etc.). This is a result of the thermodynamic and mechanical properties of Ta being much closer to those of $\mathrm{Cu}$ [17]. Thus, even if the $\mathrm{Cu}$-Ta system is still the immiscible metals system [17], compared with the $\mathrm{W}$ coating, the Ta coating can realize the cohesive combination with the Cu substrate by means of DGP surface alloying treatment.
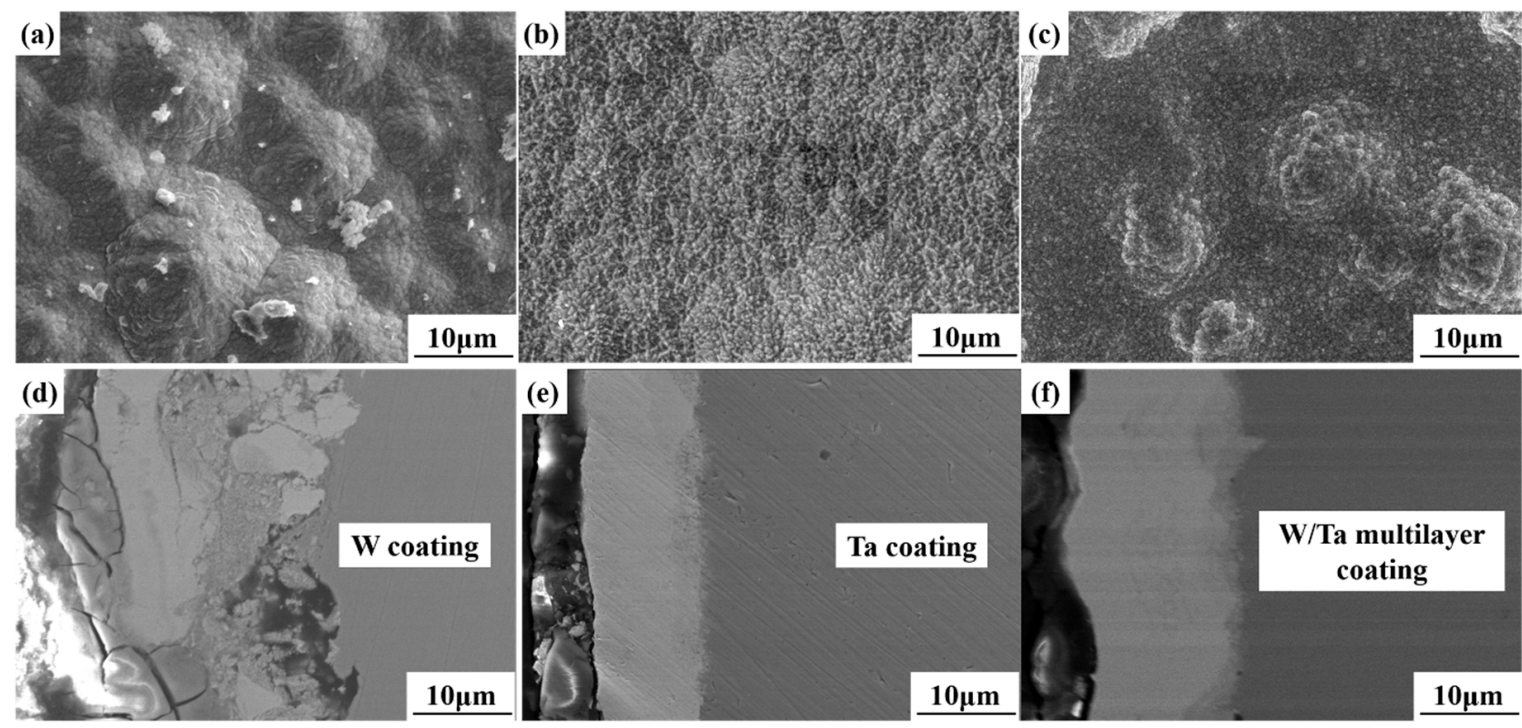

Figure 2. Surface and cross-sectional SEM micrographs of coatings: (a,d) W coating, (b,e) Ta coating, and $(\mathbf{c}, \mathbf{f}) \mathrm{W} /$ Ta multilayer coating.

The cross-section SEM micrographs of the W/Ta multilayer coating with a transition matrix are shown in Figures $2 \mathrm{f}$ and 3a. It can be clearly observed that the thickness of the obvious W/Ta coating is about $20 \mu \mathrm{m}$, which is compact, even, and has no visible imperfections. From Figure $3 b$, the EDS analysis shows a decrease in W content crossing region I and region II, and an increase in $\mathrm{Cu}$ content crossing region II and region III. Particularly, from external to internal, the Ta content increases gradually crossing region I and region II, arrives at a turning point, and then gradually declines in region III. Apparently, the interdiffusion between the W element and Ta element accomplished the metallurgical bonding between the $\mathrm{W}$ coating and Ta transition layer in region I and II. Furthermore, in region III, the $\mathrm{Cu}$ element and Ta element generated the interdiffusion during the alloying process, 
realizing the metallurgical bonding between the substrate and Ta transition layer. These results show that the distance of the total W/Ta coating alloying-affected region is about $30 \mu \mathrm{m}$, including regions I, II, and III.
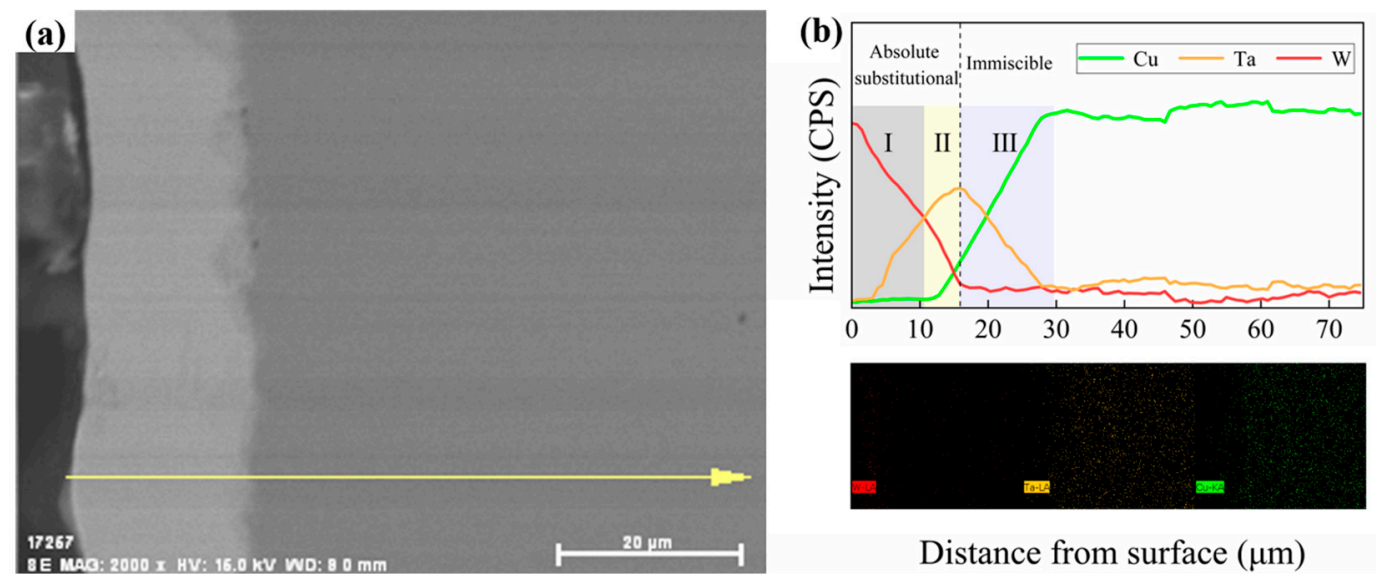

Distance from surface $(\mu \mathrm{m})$

Figure 3. Cross-sectional SEM micrograph and EDS analysis of W/Ta multilayer coating: (a) cross-sectional microstructure and (b) cross-sectional composition distribution.

The XRD patterns of the W/Ta multilayer coating (surface and transition layer) are shown in Figure 4. It is clear that the surface layer nearly shows $\alpha$-W peaks, while the transition layer mostly shows $\alpha$-Ta peaks. The locations of the $\alpha$-W and $\alpha$-Ta peaks were detected from the powder diffraction files (ICSD Patterns Database Collection Code 89-4900 and ICSD Patterns Database Collection Code 89-4901).

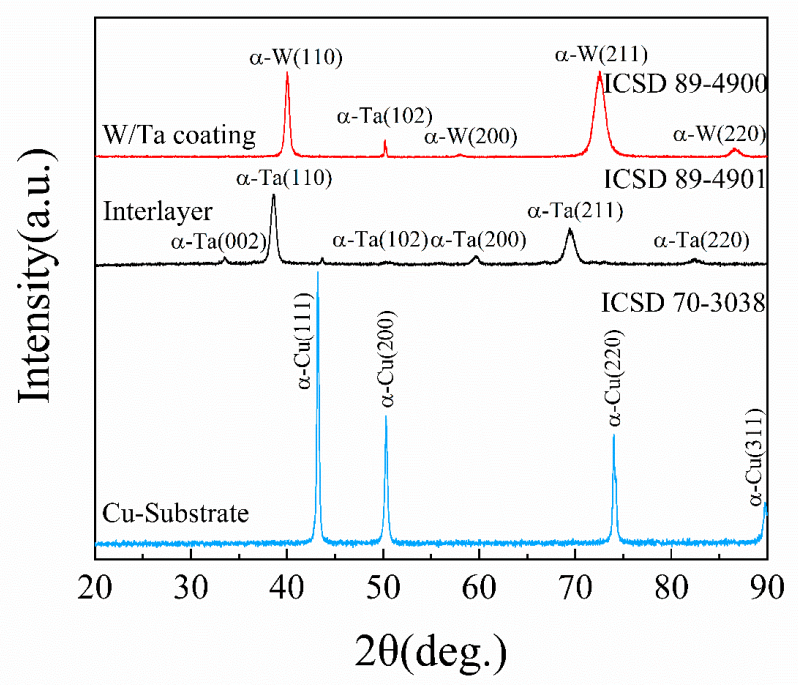

Figure 4. X-ray diffraction pattern of $\mathrm{Cu}$ substrate, interlayer, and W/Ta coating.

In combination with the analysis from the binary alloy phase diagram of the Ta-W system $[18,19]$, because the $\mathrm{W}$ element and Ta element easily formed the absolute substitutional solid solution during this surface alloying process, the solid solution ( $\alpha-\mathrm{W}$ phase) occupied the main body position in region I, which was attributed to Ta atoms solubilizing in the $\alpha-\mathrm{W}$ phase. Furthermore, the $\alpha$-Ta phase, the solid solution strengthening phase formation on account of $W$ atoms solubilizing in the $\alpha$-Ta phase, played a major role in region II. However, in region III, it is particularly obvious that $\mathrm{Cu}$ and Ta are two immiscible elements featured with a positive heat of formation of $+3 \mathrm{~kJ} / \mathrm{mol}$ and no equilibrium $\mathrm{Cu}-\mathrm{Ta}$ alloy can be observed in its equilibrium phase diagram [20]. So, even the Ta element and Cu element generated the interdiffusion during the DGP surface alloying process; they still exist separately as the 
modality of each crystal lattice in the region III and the crystal boundaries are slightly deformed with interaction, which consents adequately with the published consequences [21].

\subsection{Mechanical Properties}

As shown in Figure 5a, due to the presence of the $\alpha-\mathrm{W}$ phase with high hardness, the surface hardness of the $\mathrm{W}$ coating increases to $\approx 800 \mathrm{HV}_{0.1}$, which is almost decuple that of the Cu substrate, while the hardness of the separate Ta coating is about $300 \mathrm{HV}_{0.1}$, falling in between. The same situation exists for the Young's modulus of these phases. Thus, the Ta coating is chosen for the interlayer to realize the transition of mechanical properties between the $\mathrm{W}$ coating and $\mathrm{Cu}$ substrate. The cross-sectional hardness of the W coating and W/Ta coating are presented in Figure $5 \mathrm{~b}$. It is clear that a sudden reduction for the cross-sectional hardness of $\mathrm{W}$ coating can be observed from external to internal. Meanwhile, the cross-sectional hardness of the W/Ta multilayer coating presents a gradient descent from $\approx 800 \mathrm{HV}_{0.1}$ to $\approx 80 \mathrm{HV}_{0.1}$ within the distance of about $30 \mu \mathrm{m}$. Based on the EDS analyses for the cross-section of the W/Ta multilayer coating in Figure 3b, this also confirms that the distance of the total W/Ta multilayer coating's alloying-affected region is about $30 \mu \mathrm{m}$, include regions I, II, and III. Then, the hardness value starts to fall after $5 \mu \mathrm{m}$ as a result of the mutual diffusion of tungsten and tantalum; in addition, the hardness further decreased with a further decrease of $\mathrm{W}$ content. According to Figures 3 and $5 \mathrm{~b}$, it can be inferred that the threshold percentage of $\mathrm{W}$ that retains high hardness at the multilayer coating surface when the tungsten content is more than two-thirds. Meanwhile, the presence of the transition interlayer (Ta layer) causes the slowly and nearly linear decline for the cross-sectional hardness of the multilayer coating, accomplishing the favorable matching of mechanical properties between the $\mathrm{W}$ coating and $\mathrm{Cu}$ substrate. It can be estimated that the multilayer coating with a gradient microstructure (including hardness and Young's modulus) could improve the toughness of the coating whilst exhibiting a better loading capacity in the wear stage [22].
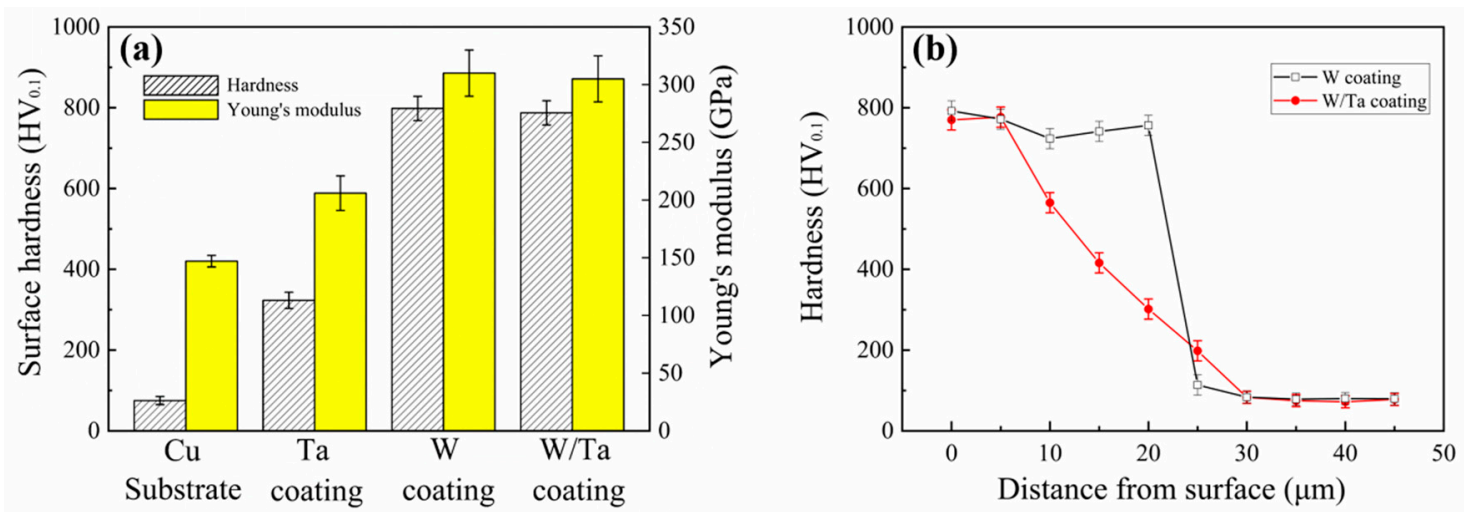

Figure 5. Mechanical properties of different specimens: (a) surface hardness and Young's modulus and (b) cross-sectional hardness of the $\mathrm{W}$ coating and W/Ta coating.

The scratched scar image and the corresponding acoustic emission spectra are shown in Figure 6. The critical loads at the single $\mathrm{W}$ coating and W/Ta multilayer coating stripped from the substrate are $\approx 6 \mathrm{~N}$ and $\approx 22 \mathrm{~N}$, respectively. Obviously, due to the assistance of the transition interlayer, the W/Ta multilayer coating has a better adhesive strength $(\approx 22 \mathrm{~N})$ than that of the single $\mathrm{W}$ coating $(\approx 6 \mathrm{~N})$. Therefore, the good design of a multilayer microstructure not merely alleviates the coating stress from interfaces usefully and enhances the adhesion, the toughness of the coating also receives a boost, which results in satisfactory mechanical properties.

\subsection{Tribological Behavior}

In terms of such coatings used in engineering applications, especially in the field of nuclear industry, the tribological behavior of these coatings is essential to be discussed. In this work, the wear-resistant 
properties of the substrate and coating specimens were compared and analyzed by measuring the wear rates and investigating the typical morphologies of wear scars at 25 and $500{ }^{\circ} \mathrm{C}$, respectively. The coefficients of friction $(\mathrm{CoF})$ and wear rates of the substrate and coating specimens are shown in Figure 7. According to Figure 7a,b, the curves of the CoFs for the coating specimens remain relatively stable in contrast with the $\mathrm{Cu}$ substrate. This is attributed to the favorable wear resistance of the coatings; only a slight plastic deformation appeared in the wear process. Nevertheless, due to the inferior wear resistance of the $\mathrm{Cu}$ substrate, severe plastic deformation appeared during the wear process, resulting in the drastic fluctuation of its CoFs. The CoF of the $\mathrm{W}$ coating is a little smaller than the $\mathrm{W} / \mathrm{Ta}$ multilayer coating at $500{ }^{\circ} \mathrm{C}$, but the $\mathrm{CoF}$ is almost at the same level. Relative to the protection of the coatings, the results of the CoF are only a guideline, and the wear resistance of the $\mathrm{W} /$ Ta multilayer coating is emphatically discussed in this paper. The reason for the reduced CoF of a single $\mathrm{W}$ coating after a certain sliding time at $500{ }^{\circ} \mathrm{C}$ is because of its poor adhesive strength and toughness. It is more prone to fracture and peel in the friction process and thus leads to obvious change in the friction coefficient. Figure $7 \mathrm{c}$ shows that the $\mathrm{Cu}$ substrate presents high wear rates, especially at $500{ }^{\circ} \mathrm{C}$, reaching $909 \times 10^{-6} \mathrm{~mm}^{3} / \mathrm{Nm}$. Meanwhile, the W/Ta multilayer coating has the lowest wear rates both at 25 and $500^{\circ} \mathrm{C}\left(104 \times 10^{-6} \mathrm{~mm}^{3} / \mathrm{Nm}\right.$ and $14 \times 10^{-6} \mathrm{~mm}^{3} / \mathrm{Nm}$, respectively $)$. Simultaneously, the wear rate of the $\mathrm{W}$ coating is slightly higher than that of the W/Ta multilayer coating just because the single $\mathrm{W}$ coating is more prone to fracture for its poor adhesive strength and toughness, as mentioned before. As a result, it is confirmed that the multilayer coating designed in this paper exhibits better adhesion, toughness, and excellent tribological properties, which can play a vital role in protecting the substrate from wear in the practical applications.

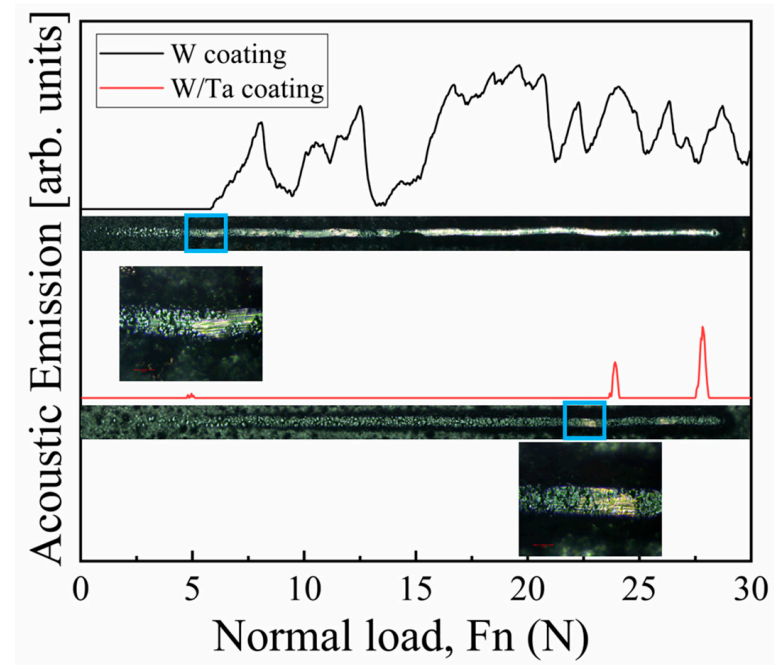

Figure 6. The scratched morphology and the corresponding acoustic emission spectra.
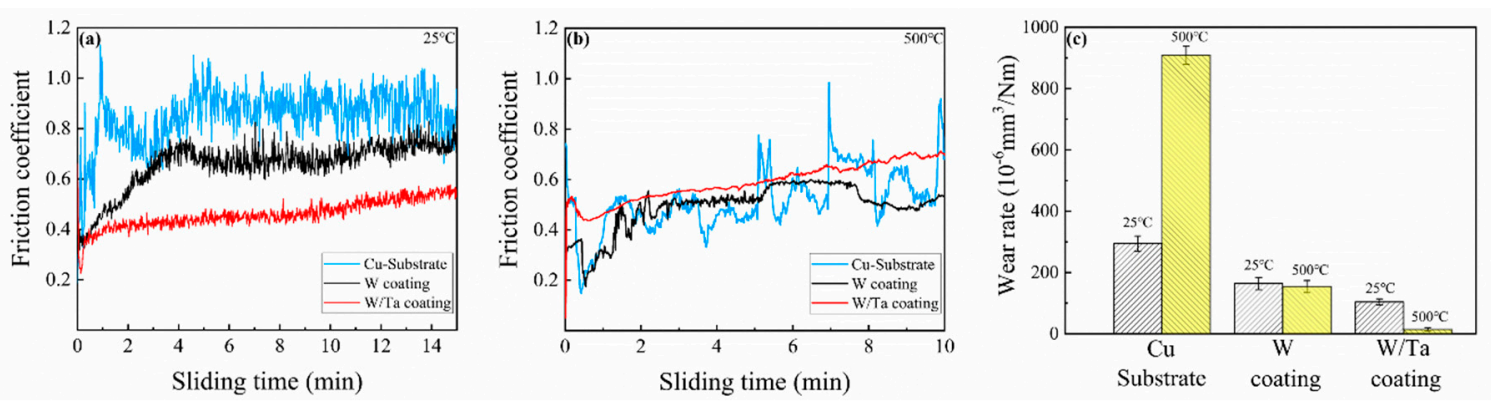

Figure 7. The tribological properties of the substrate and coating specimens: (a) the coefficients of friction $(\mathrm{CoFs})$ at $25^{\circ} \mathrm{C},(\mathbf{b})$ the $\mathrm{CoFs}$ at $500{ }^{\circ} \mathrm{C}$, and (c) wear rates of specimens at 25 and $500{ }^{\circ} \mathrm{C}$. 
The wear scar morphologies of the substrate and coating samples at $25^{\circ} \mathrm{C}$ are shown in Figure 8 . On account of severe plastic deformation, numerous tears and extensive adhesive areas can be observed on the wear scar of the $\mathrm{Cu}$ substrate in Figure $8 \mathrm{a}$, which presents poor wear resistance at a macro level, revealing that the adhesive wear mechanism predominated in the wear process. From Figure $8 \mathrm{c}$, the wear scar of the W/Ta multilayer coating shows that a slight abrasion appeared during the wear process, and only the shallow scratch and slight wear debris can be observed. The wear mechanism was mainly abrasive wear; this was attributed to the hard phase $(\alpha-W)$ of the $W / T a$ multilayer coating, which provided positive protection to reduce the wear rates for the aim of improving wear resistance [23]. In addition, the single $\mathrm{W}$ coating is easy to tear during the wear process on account of its bad adhesive strength and toughness. Thus, the peeling and chipping are observed on the edge of the wear track, as shown in Figure 8b, which leads to the higher wear rate compared with the multilayer coating. Furthermore, the tribological behavior of the substrate and coating samples at high temperature was investigated. In contrast to the room temperature, the oxidative wear mechanism has been regarded as the primary reason for the failure of the material surface at high temperature [24]. The wear scar morphologies of the substrate and coating samples at $500{ }^{\circ} \mathrm{C}$ are shown in Figure 9 . At $500{ }^{\circ} \mathrm{C}$, the severe oxidative wear induced the $\mathrm{Cu}$ surface plastic flow drastically during the wear process, producing more extensive adhesive areas along with adhesive wear. In this case, the wear rate remarkably increases up to $909 \times 10^{-6} \mathrm{~mm}^{3} / \mathrm{Nm}$, and the main wear mechanism of the substrate is oxidative wear and adhesive wear. While the defects of $\mathrm{W}$ coating, such as poor adhesion and toughness, would generate negative effects at high temperature. It is obvious that the $\mathrm{W}$ coating was more likely to peel during the wear process, and these peeling areas were easier to generate oxidative and adhesive wear, as evidenced by Figure $9 c$, bringing out a conspicuous increase of the wear rate. As presented in Figure 9e, only slight wear debris can be observed in the wear scar. It is reasonable that the W/Ta multilayer coating with better comprehensive mechanical performance (better adhesion and toughness) would exhibit excellent oxidative wear resistance at high temperature, contributing the lowest wear rate $\left(14 \times 10^{-6} \mathrm{~mm}^{3} / \mathrm{Nm}\right)$, which was even less than that of this specimen at room temperature. Simultaneously, tantalum has a high affinity for interstitial gases $(\mathrm{O}, \mathrm{N}, \mathrm{C}$, and $\mathrm{H})$, and the resulting compounds are very stable, even at elevated temperatures. Therefore, it is considered that Ta addition is beneficial to improve the oxidation resistance [25]. Here, the abrasive wear mainly constitutes the wear mechanism.

\subsection{Deformation Mechanism during Scratching}

The scratch test was executed to study the deformation mechanism of the $\mathrm{W}$ coatings under stress. The variations of the normal force, $\mathrm{CoF}$, and penetration depth during the scratch experiment for the $\mathrm{W}$ coating and W/Ta multilayer coating are given in Figure 10a,b, respectively. As previously mentioned, compared with the $\mathrm{W}$ coating, the presence of the transition interlayer in the W/Ta multilayer coating could improve the binding strength and increase the toughness of the coating. The results obtained by the scratch test were presented in Xu's paper [26], where the correlation among $\mathrm{Ft}$, $\mathrm{Fn}$, and deformation of copper surface by $\mathrm{CeO}_{2}$ under ramped loading was analyzed. The deformation mechanism also could be validated by the correlation between $\mathrm{CoF}$ and Fn. Bowden-Tabor [27] proposed three evident stages of $\mathrm{CoF}$ with Fn during a discrepant course of deformation, as presented by: elastic deformation,

$$
\mu \propto F_{n}^{-1 / 3}
$$

changing elastic-plastic deformation,

$$
\mu \propto F_{n}^{m}(0<\mathrm{m}<1) \text {, and }
$$

stable elastic-plastic deformation,

$$
\mu \propto F_{n}^{0}
$$



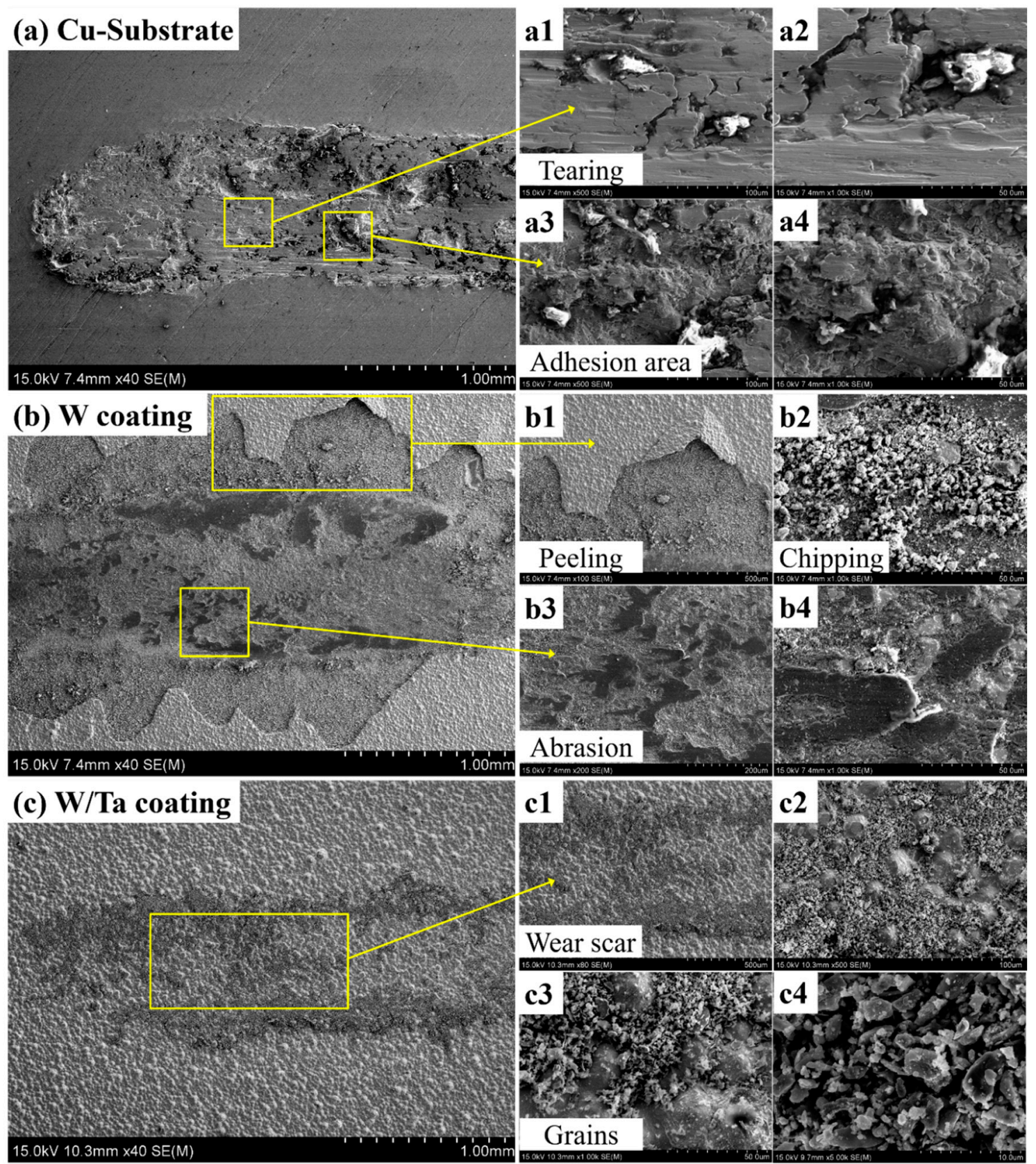

Figure 8. Morphologies of substrate and coated specimens after a tribological test at $25^{\circ} \mathrm{C}:(\mathbf{a}, \mathbf{a} 1-\mathbf{a} 4)$ Cu substrate, (b,b1-b4) W coating, and (c,c1-c4) W/Ta coating. 


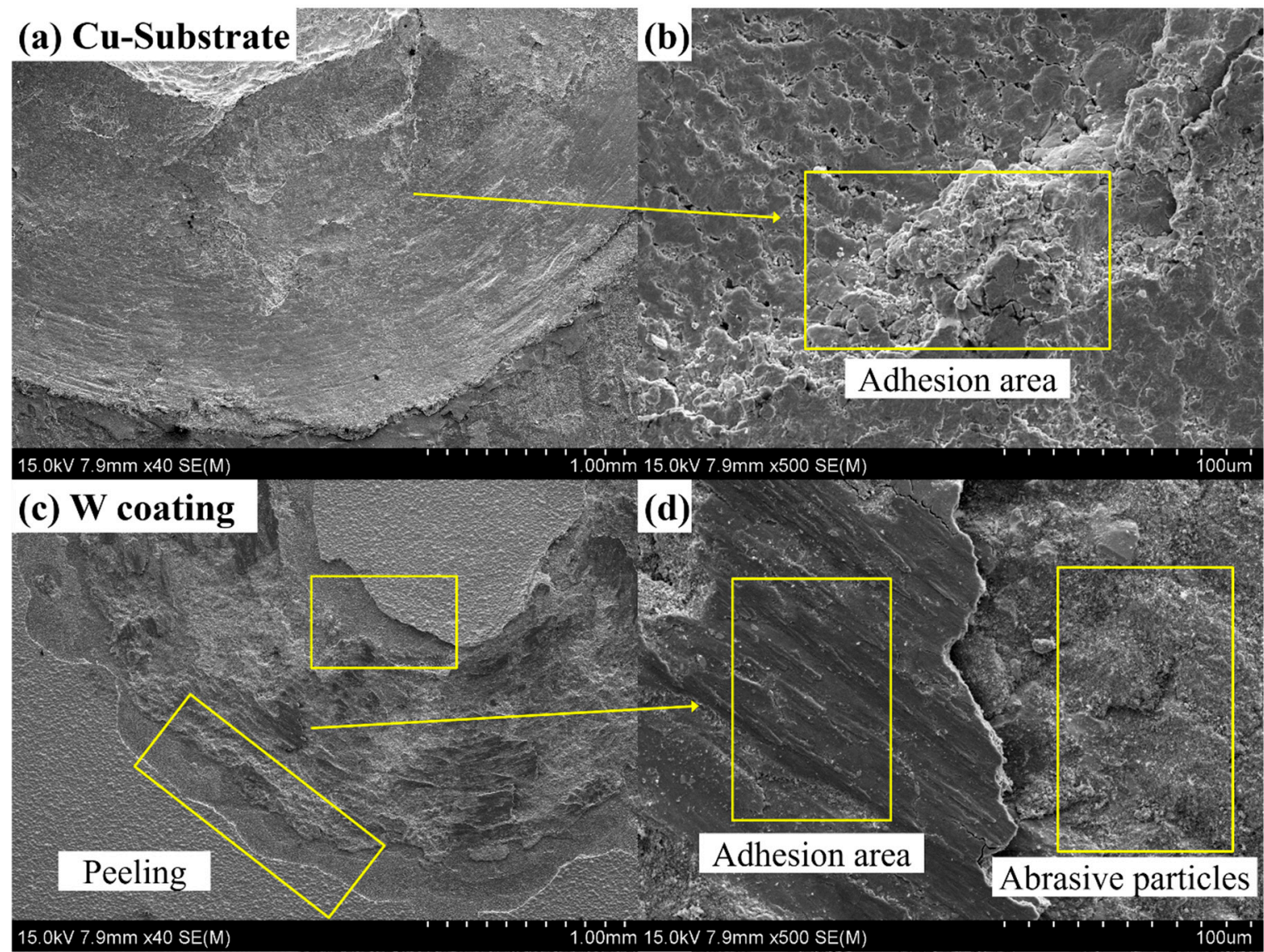

(e) W/Ta coating

(f)

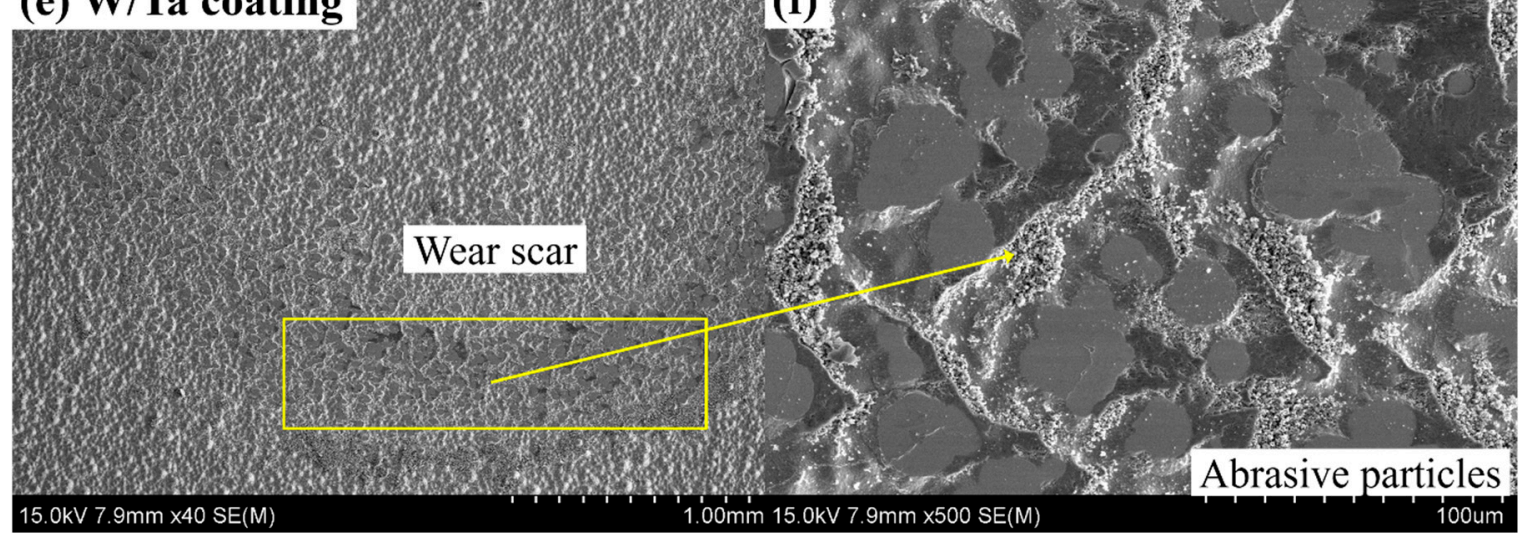

Figure 9. Morphologies of substrate and coated specimens after a tribological test at $500{ }^{\circ} \mathrm{C}:(\mathbf{a}, \mathbf{b}) \mathrm{Cu}$ substrate, (c,d) W coating, and (e,f) W/Ta coating. 

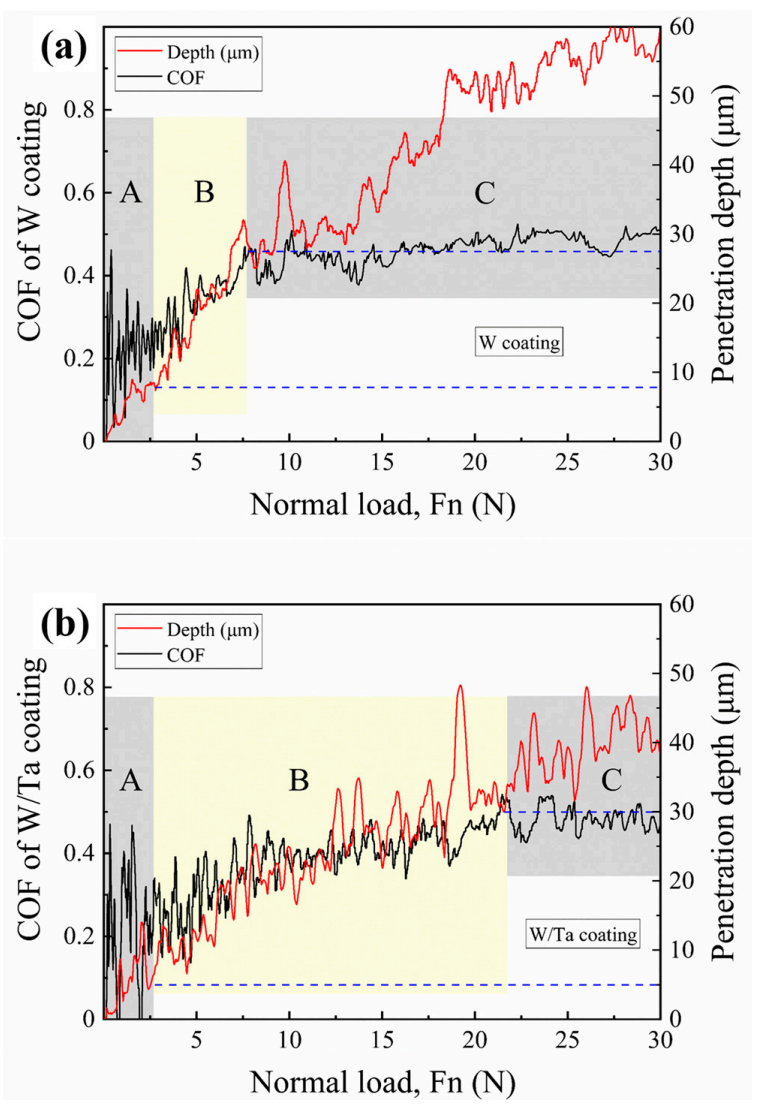

Figure 10. Variation of normal force, $\mathrm{CoF}$, and penetration depth during the scratch experiment for (a) W coating and (b) W/Ta coating.

From this theoretical perspective, both the changing elastic-plastic and elastic mechanisms are reasonable for wear behavior, which has been referred to the published consequences [28].

As shown in Figure 10, it is obvious that similar three stages are presented through the curves of CoF both in the W coating and W/Ta multilayer coating, matching with Equations (3) and (4) on the basis of the theory of Bowden-Tabor. Accompanied with the escalation in normal force, the CoF fluctuates incipiently $\approx 0.2$ in stage $\mathrm{A}$; afterwards, it increases from $\approx 0.2$ to $\approx 0.5$ in stage $\mathrm{B}$, and it ultimately fluctuates $\approx 0.6$ in stage $C$. Here, the prime difference between the $\mathrm{W}$ coating and the $\mathrm{W} / \mathrm{Ta}$ multilayer coating is that the $\mathrm{CoF}$ of the $\mathrm{W} / \mathrm{Ta}$ multilayer coating reveals a more gradual increase in stage $B$ from $\approx 2$ to $\approx 22 \mathrm{~N}$ under stress, while that of the $\mathrm{W}$ coating presents a sudden increase from $\approx 2$ to $\approx 7 \mathrm{~N}$. According to the above results shown in Figure 6, the persistence of the changing elastic-plastic deformation in the W/Ta multilayer coating can improve the adhesion and the resistance to plastic deformation. Furthermore, combining with the results of the penetration depth of coatings under the scratch test, it was found distinctly that the W/Ta multilayer coating exhibits better tribological performance than the $\mathrm{W}$ coating.

In consequence, it can be indicated that the transition interlayer plays a vital part in the multilayer design in two aspects. For one thing, due to the persistence stage of the changing elastic-plastic deformation of the W/Ta multilayer coating being more than that of the W coating, the toughness of the coating obtains a great promotion to resist the brittle deformation. Simultaneously, the addition of a transition interlayer increases the critical normal force from $\sim 7$ to $\sim 22 \mathrm{~N}$, which extends the deformation transition from changing elastic-plastic to stable elastic-plastic regions. In addition, the contribution of the transition interlayer to abrasion resistance can be expressed by the lower penetration depth. Thus, the changing elastic-plastic deformation region can be reasonably expected to contribute to the friction process, and the mechanical properties of the transition layer present a linear gradient descent instead of a vertical gradient, which make a substantial contribution in the wear stage. As evidenced 
by the wear scars of different specimens in Figures 8 and 9, the transition interlayer region produced significant protection against deformation, providing a lower wear rate in contrast to the substrate and $\mathrm{W}$ coating, as only some abrasive particles can be observed without cracks. In the case of the W/Ta multilayer coating, from the viewpoint of composite coating design, the deformation mechanism under stress also should be considered as an important parameter.

\section{Conclusions}

1. A W/Ta multilayer coating was designed and deposited on the surface of pure copper by DGP surface alloying technology. As a result of the presence of $\alpha-\mathrm{W}$ phase with high hardness, the surface hardness of coatings increases to $\approx 800 \mathrm{HV}_{0.1}$, which is almost decuple that of the $\mathrm{Cu}$ substrate. Compared to the separate W coating, the W/Ta multilayer coating exhibits the preferable adhesive strength and sufficient toughness due to the existence of a transition interlayer (Ta layer), accomplishing the favorable matching of mechanical properties between the $\mathrm{W}$ coating and $\mathrm{Cu}$ substrate.

2. The separate $\mathrm{W}$ coating was more likely to peel during the wear process due to its poor adhesive strength and toughness, and these peeling areas were easier to generate oxidative and adhesive wear. The good design of a multilayer microstructure made a critical difference in enhancing the wear resistance, leading to the lowest wear rate of $14 \times 10^{-6} \mathrm{~mm}^{3} / \mathrm{Nm}$, which was greatly less than the substrate or the separate $\mathrm{W}$ coating. Furthermore, the wear mechanism of the multilayer coating was mainly abrasive wear.

3. The addition of a transition interlayer, causing the persistence stage of changing elastic-plastic deformation of the W/Ta multilayer coating to be more than that of the $\mathrm{W}$ coating, makes a significant contribution in affecting the deformation of the coating under stress. In addition, the extension of changing elastic-plastic deformation is salutary to the wear course, resulting in the mechanical properties of the coating presenting a linear gradient descent instead of a vertical gradient, which makes a substantial contribution in the wear stage.

Author Contributions: Conceptualization, B.D. and T.T.; methodology, B.D., F.L., and K.Y.; validation, T.T. and P.Z.; investigation, K.Y., F.D., and D.W.; resources, P.Z. and D.W.; writing-original draft preparation, B.D. and T.T.; writing - review and editing, B.D., K.Y., and T.T. All authors have read and agreed to the published version of the manuscript.

Funding: This project was supported by the Natural Science Foundation for Excellent Young Scientists of Jiangsu Province, China (Grant No. BK20180068), China Postdoctoral Science Foundation funded project (Grant No. 2018M630555), Opening Project of Materials Preparation and Protection for Harsh Environment Key Laboratory of Ministry of Industry and Information Technology (Grant No. XCA20013-1), Opening Project of Jiangsu Key Laboratory of Advanced Structural Materials and Application Technology (Grant No. ASMA201701), the Fundamental Research Funds for the Central Universities, China (Grant No. NS2018039).

Conflicts of Interest: The authors declare no conflict of interest.

\section{References}

1. Linke, J. Plasma facing materials and components for future fusion devices-development, characterization and performance under fusion specific loading conditions. Phys. Scr. 2006, T123, 45-53. [CrossRef]

2. Bolt, H.; Barabash, V.; Federici, G.; Linke, J.; Loarte, A.; Roth, J.; Sato, K. Plasma facing and high heat flux materials-needs for ITER and beyond. J. Nucl. Mater. 2002, 307, 43-52. [CrossRef]

3. Huang, Y.; Du, J.L.; Wang, Z. Progress in research on the alloying of binary immiscible metals. Acta Metall. Sin. 2020, 56, 801-820. [CrossRef]

4. Lu, G.H.; Zhou, H.B.; Becquart, C.S. A review of modelling and simulation of hydrogen behaviour in tungsten at different scales. Nucl. Fusion. 2014, 54, 086001. [CrossRef]

5. Meng, Y.F.; Zhang, J.P.; Duan, C.Y.; Chen, C.; Feng, X.M.; Shen, Y.F. Microstructures and properties of W-Cu functionally graded composite coatings on copper substrate via high-energy mechanical alloying method. Adv. Powder Technol. 2015, 26, 392-400. [CrossRef] 
6. Philipps, V. Tungsten as material for plasma-facing components in fusion devices. J. Nucl. Mater. 2011, 415, S2-S9. [CrossRef]

7. Wen, S.P.; Zong, R.L.; Zeng, F.; Gao, Y.; Pan, F. Evaluating modulus and hardness enhancement in evaporated $\mathrm{Cu} / \mathrm{W}$ multilayers. Acta Mater. 2007, 55, 345-351. [CrossRef]

8. Liu, Y.H.; Zhang, Y.C.; Liu, Q.Z.; Li, X.L.; Jiang, F. Electro-deposition metallic tungsten coatings in a $\mathrm{Na}_{2} \mathrm{WO}_{4}-\mathrm{WO}_{3}$ melt on copper based alloy substrate. Fusion Eng. Des. 2012, 87, 1861-1865. [CrossRef]

9. Monclús, M.A.; Karlik, M.; Callisti, M.; Frutos, E.; Llroca, J.; Pplcar, T.; Molina-Aldareguía, J.M. Microstructure and mechanical properties of physical vapor deposited $\mathrm{Cu} / \mathrm{W}$ nanoscale multilayers: Influence of layer thickness and temperature. Thin Solid Film. 2014, 571, 275-282. [CrossRef]

10. Wang, T.G.; Chen, J.L.; Chen, Y.; Wu, Y.C. Thermal properties of VPS-W coatings on CuCrZr alloy with Ti bonding layer. J. Nucl. Mater. 2007, 363, 1294-1298. [CrossRef]

11. Zhang, J.; Huang, Y.; Wang, Z.; Liu, Y.C. Thermodynamic mechanism for direct alloying of immiscible tungsten and copper at a critical temperature range. J. Alloys Compd. 2018, 774, 939-947. [CrossRef]

12. Qiu, Z.K.; Zhang, P.Z.; Wei, D.B.; Wei, X.F.; Chen, X.H. A study on tribological behavior of double-glow plasma surface alloying W-Mo coating on gear steel. Surf. Coat. Technol. 2015, 278, 92-98. [CrossRef]

13. Yi, J.W.; Miao, Q.; Liang, W.P.; Ding, Z.; Qi, Y.; Lin, H.; Huang, C.J. A study for pre-processing of Nb diffusion in $\mathrm{Nb}-\mathrm{N}$ layer by double-glow plasma alloying. J. Alloys Compd. 2020, 820, 153121. [CrossRef]

14. Li, J.X.; Chen, Y.H.; Bai, Z.J.; Zhao, B.J.; Jiang, L. Oxidation behavior of multi-component Ta-W-Al-Ti alloy at 1173K. Rare Met. 2020, 39, 1-9. [CrossRef]

15. Dias, M.; Guerreiro, F.; Correia, J.B.; Galatanu, A.; Rosiński, M.; Monge, M.A.; Munoz, A.; Alves, E.; Carvalho, P.A. Consolidation of $\mathrm{W}$-Ta composites: Hot isostatic pressing and spark and pulse plasma sintering. Fusion Eng. Des. 2015, 98, 1950-1955. [CrossRef]

16. Liu, X.; Zhang, F.; Tao, S.Y.; Cao, Y.Z.; Xu, Z.Y.; Liu, Y.; Noda, N. Research and development of plasma sprayed tungsten coating on graphite and copper substrates. J. Nucl. Mater. 2007, 363, 1299-1303. [CrossRef]

17. Parchuri, P.; Kotegawa, S.; Yamamoto, H.; Ito, K.; Mori, A.; Hokamoto, K. Benefits of intermediate-layer formation at the interface of $\mathrm{Nb} / \mathrm{Cu}$ and $\mathrm{Ta} / \mathrm{Cu}$ explosive clads. Mater. Des. 2019, 166, 107610. [CrossRef]

18. Peng, X.M.; Xia, C.Q.; Zhou, L.; Huang, L.; Li, D.F.; Wu, A.R. Study of arc ion plated Ta-W coating on a titanium alloy. Surf. Coat. Technol. 2018, 349, 622-635. [CrossRef]

19. Li, X.B.; Zhang, P. Phase stability of Ta-W alloys. Acta Metall. Sin Eng. Lett. 2010, 23, 215-222.

20. Gong, H.R.; Liu, B.X. Interface stability and solid-state amorphization in an immiscible Cu-Ta system. Appl. Phys. Lett. 2003, 83, 4515. [CrossRef]

21. Zhang, J.; Huang, Y.; Liu, Y.C.; Wang, Z.M. Direct diffusion bonding of immiscible tungsten and copper at temperature close to Copper's melting point. Mater. Des. 2018, 137, 473-480. [CrossRef]

22. Kabir, M.S.; Munroe, P.; Zhou, Z.F.; Xie, Z.H. Scratch adhesion and tribological behaviour of graded $\mathrm{Cr} / \mathrm{CrN} / \mathrm{CrTiN}$ coatings synthesized by closed-field unbalanced magnetron sputtering. Wear 2017, 380, 163-175. [CrossRef]

23. Kovářík, O.; Haušild, P.; Siegl, J.; Chráska, T.; Matějiček, J.; Pala, Z.; Boulos, M. The influence of substrate temperature on properties of APS and VPS W coatings. Surf. Coat. Technol. 2015, 268, 7-14. [CrossRef]

24. Qiu, J.W.; Fu, Z.F.; Liu, B.; Liu, Y.; Yan, J.H.; Pan, D.; Zhang, W.D.; Baked, I. Effects of niobium particles on the wear behavior of powder metallurgical $\gamma$-TiAl alloy in different environments. Wear 2019, 434, 202964. [CrossRef]

25. Gao, S.; He, B.; Zhou, L.Z.; Hou, J.S. Effects of Ta on the high temperature oxidation behavior of IN617 alloy in air. Corros. Sci. 2020, 170, 108682. [CrossRef]

26. Xu, N.; Han, W.Z.; Wang, Y.C.; Li, J.; Shan, Z.W. Nanoscratching of copper surface by $\mathrm{CeO}_{2}$. Acta Mater. 2017, 124, 343-350. [CrossRef]

27. Bhushan, B. Modern Tribology Handbook; CRC Press: Boka Raton, FL, USA, 2001.

28. Wang, Y.G.; Chen, Y.; Zhao, D.; Lu, X.L.; Liu, W.W.; Qi, F.; Chen, Y. Deformation mechanism of CrN/nitriding coated steel in wear and nano-scratch experiments under heavy loading conditions. Appl. Surf. Sci. 2018, 447, 100-106. [CrossRef]

(C) 2020 by the authors. Licensee MDPI, Basel, Switzerland. This article is an open access article distributed under the terms and conditions of the Creative Commons Attribution (CC BY) license (http://creativecommons.org/licenses/by/4.0/). 